\title{
Crystal structure of the $\mathrm{F}$ component of the Panton-Valentine leucocidin
}

\author{
Jean-Denis Pédelacq ${ }^{1}$, Gilles Prévost ${ }^{2}$, Henri Monteil ${ }^{2}$, Lionel Mourey', Jean-Pierre Samama ${ }^{1}$
}

${ }^{1}$ Groupe de Cristallographie Biologique, Institut de Pharmacologie et de Biologie Structurale du CNRS, 205 route de Narbonne, 31077 Toulouse cedex, France

${ }^{2}$ Laboratoire de Toxinologie et d'Antibiologie Bactériennes, Institut de Bactériologie de la Faculté de Médecine, 3 rue Koeberlé, 67000 Strasbourg, France

\begin{abstract}
Leucocidins and $\gamma$-hemolysins are bi-component staphylococcal toxins that form lytic transmembrane pores. Their cytotoxic activities involve the synergistic association of a class $S$ and a class $F$ component, produced as water-soluble monomers which assemble on the surface of specific cells. The structure of the F protein from Panton-Valentine leucocidin, solved at $2.0 \AA$ resolution, and sequence alignment suggest that it represents the fold of any secreted protein in this family of toxins. The comparison of this structure to that of the homoheptameric $\alpha$-hemolysin provides some insights into the molecular events that may occur during pore formation.
\end{abstract}

Key words: crystal structure - Panton-Valentine leucocidin - lytic transmembrane pores

\section{Introduction}

Staphylococcus aureus, one of the most prevalent human pathogens isolated in hospitals, produces a host of toxins that includes $\alpha$-hemolysin $(\alpha-H L), \gamma$-hemolysins (Hlg), and leucocidins (Luk) (for a review, see (Tomita and Kamio, 1997)). These toxins are secreted as watersoluble protein monomers which assemble on the surface of host cells to form oligomeric transmembrane channels (Finck-Barbançon et al., 1993; Sugawara et al., 1997). Hlg and Luk, but not $\alpha$-HL, form the family of staphylococcal bi-component leucotoxins (Prévost et al., 1995). Their toxicity involves the synergistic action of a class $S$ and a class $F$ component (Woodin, 1960) and is essentially directed against host defence cells, e.g. polymorphonuclear cells, monocytes, macrophages, and erythrocytes.

Several leucocidins and $\gamma$-hemolysins have been isolated from various $S$. aureus strains and from $S$. intermedius (Cooney et al., 1993; Rahman et al., 1993; Kaneko et al., 1997; Prévost, 1999). Among these toxins, the Panton-Valentine leucocidin (PVL) was the first to be reported and characterized (Panton and Valentine, 1932; Woodin, 1960). PVL-producing strains are associated with primary cutaneous infections such as furuncles (Prévost, 1999), and the toxin was shown to be highly active on human and rabbit polymorphonuclear leucocytes (Finck-Barbançon et al., 1993; Prévost et al., 1995).

The first event of the mode of action of PVL is the interaction of the $\mathrm{S}$ component (LukS-PV) (Colin et al., 1994) with a membrane-bound target, followed by the binding of LukF-PV (Woodin and Wieneke, 1968; Noda et al., 1981). These sequential interactions at the membrane surface induce a $\mathrm{Ca}^{2+}$ influx through the opening of $\mathrm{Ca}^{2+}$ channels (Staali et al., 1998), the activation of the targeted cells (König et al., 1995), and the formation of pores which are specific for the traffic of monovalent cations (Finck-Barbançon et al., 1993; Meunier et al., 1995; Staali et al., 1998). Biochemical and biophysical studies indicated that bi-component toxins form membrane-attached heteromers and

Corresponding author: Jean-Pierre Samama, Groupe de Cristallographie Biologique, Institut de Pharmacologie et de Biologie Structurale du CNRS, 205 route de Narbonne, F-31077 Toulouse cedex, France, Phone: +33561 1754 44, Fax: +33 561 1754 48, E-mail: samama@ipbs.fr 
argued for hexameric assemblies containing similar amounts of $F(M W=34 \mathrm{kDa})$ and $\mathrm{S}(\mathrm{MW}=32 \mathrm{kDa})$ components (Sugawara et al., 1997; Ferreras et al., 1998).

Our goal was to describe the molecular species at the first step of pore formation, i. e. as the monomeric form that approaches the membrane surface. We have crystallized the secreted LukF-PV (301 residues) and solved its crystallographic structure at $2.0 \AA$ resolution. This study shows the conservation of the core domains between the Luk, Hlg, and $\alpha$-HL (Song et al., 1996) proteins, and illustrates the fold of the stem domain of these proteins prior to membrane insertion.

\section{Materials and methods}

Methods used for the structure determination of LukF-PV have been described recently (Pédelacq et al., 1999). Briefly, the protein was purified from the reference S.aureus ATCC49775 using Fast Performance Liquid Chromatography (Finck-Barbançon et al., 1991) and crystallized at $4^{\circ} \mathrm{C}$ using the hanging drop diffusion method in the presence of PEG and divalent cations at neutral $\mathrm{pH}$. The structure was determined using the Multiwavelength Anomalous Dispersion (MAD) method on a single crystal soaked with an iridium derivative, and refined at 2.0 Â resolution.

\section{Results and discussion}

\section{Crystallographic studies}

Two crystal forms of LukF-PV were obtained (Table 1) and in both cases, crystal growth required the design of appropriate seeding protocols. The orthorhombic crystals (Figure 1) diffracted to higher resolution and were used for structure determination. Solving the

Table 1. Characteristics of the two crystal forms of LukF-PV.

\begin{tabular}{|c|c|c|}
\hline Crystal form & Plate (trigonal) & Bar (orthorhombic) \\
\hline $\begin{array}{l}\text { Crystallization } \\
\text { conditions } \\
\text { (equilibrium) }\end{array}$ & $\begin{array}{l}\text { PEG4000 } 8 \% \\
\text { Hepes, Tris } 80 \mathrm{mM} \\
\mathrm{pH} 7.5 \\
\mathrm{MgCl}_{2} 53 \mathrm{mM}\end{array}$ & $\begin{array}{l}\text { PEG4000 } 21 \% \\
\text { MES, Tris } 200 \mathrm{mM} \\
\mathrm{pH} 6.8-7.0 \\
\mathrm{CdCl}_{2} 7 \mathrm{mM}\end{array}$ \\
\hline Space group & $P 3,21$ & $P 2_{1} 2_{1} 2_{1}$ \\
\hline Cell parameters $(\AA)$ & $\begin{array}{l}a=50.6, b=50.6 \\
c=247.7\end{array}$ & $\begin{array}{l}a=50.7, b=73.3, \\
c=99.7\end{array}$ \\
\hline$N^{\circ}$ molecules/a. u. ${ }^{1}$ & 1 & 1 \\
\hline Diffraction limit $(\AA A)^{2}$ & 3.2 & 1.8 \\
\hline
\end{tabular}

\footnotetext{
1 asymmetric unit.

2 Determined using synchrotron radiation. Recently, a diffraction limit of $1.2 \AA$ was attained with orthorhombic crystals on beam line ID14-EH4 at ESRF (Grenoble, France).
}

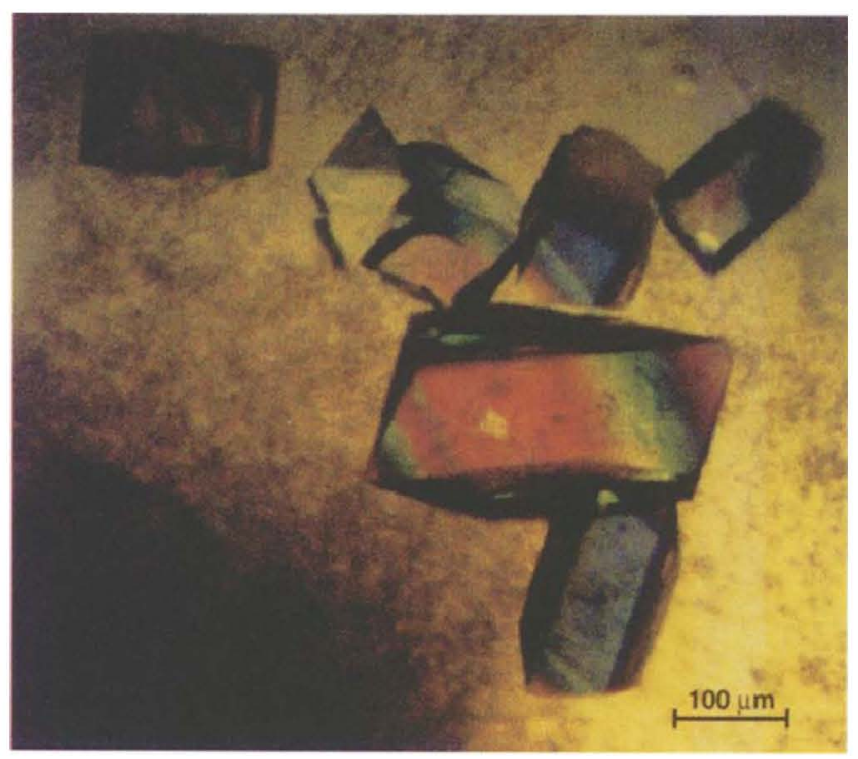

Fig. 1. Orthorhombic crystals of LukF-PV.

phase problem by the multiple isomorphous replacement (MIR) method was impaired by severe non isomorphism upon heavy atom binding. We therefore performed a MAD experiment from a single crystal soaked in a solution of the hexachloroiridate salt $\left(\mathrm{NH}_{4}\right)_{2} \mathrm{IrCl}_{6}$. The data were collected to $2.0 \AA$ resolution at the EMBL Hamburg outstation beam line X31. The intensities were measured at four wavelengths which were chosen according to the fluorescence spectrum of the iridium derivative in the cryocooled crystal (Pédelacq et al., 1999). MAD phasing using seven heavy-atom sites, followed by solvent flattening, led to an initial electron density map of high quality (Figure 2) which allowed tracing of most of the LukF-PV molecule. Structure refinement was conducted between 24.4 and $2.0 \AA$. The final crystallographic $R$ and $R_{\text {free }}$ values were 0.20 and 0.24 , respectively.

\section{Overall structure}

LukF-PV is a global protein of ellipsoidal shape with overall dimensions $75 \AA \times 30 \AA \times 20 \AA$. Most residues are engaged in secondary structure elements. There are $22 \beta$ strands and three short helices which involve $64.4 \%$ and $5.3 \%$ of protein residues, respectively. These secondary structure elements delineate three structural domains: the $\beta$-sandwich, the rim, and the folded stem (Figure 3 ). The $\beta$-sandwich domain (residues 1-61, 80-102, 154-169, 219-249, and 268301 ) is made of two six-stranded antiparallel $\beta$-sheets (strands S1, S2, S3, S4, S6, and S5, and strands SD, SE, $\mathrm{SA}, \mathrm{SF}, \mathrm{SG}$, and $\mathrm{SH}$ ) facing each other. The rim domain (residues 62-79, 170-218, 250-267) forms an antiparallel four-stranded open-face sandwich (strands 
SR1, SR2, SF, and SR5) topped by residues 182-218. This stretch can be described as two consecutive omega loops followed by all the helical segments $(\mathrm{H} 1, \mathrm{H} 2$, H3) found in LukF-PV. The folded stem region, made of residues 106-148, includes three antiparallel $\beta$ strands (ST1, ST2, ST3) linked by one $\beta$-turn and one right-handed crossover connection. The junction of the stem domain to the $\beta$-sandwich domain is provided by two short antiparallel strands SB (103-105) and SC (149-153).

The structure of LukF from the Smith 5R strain of S. aureus, was reported recently (Olson et al., 1999). It displays a similar architecture to that of LukF-PV.

\section{Structural conservation among staphylococcal pore-forming toxins}

The core of LukF-PV, made of the $\beta$-sandwich and of the rim domains, is similar to that of the $\alpha$-HL protomer (Song et al., 1996; Gouaux et al., 1997). Superposition of the two protein structures can be achieved using either the sandwich or the rim domains (Figure 4). These domains undergo rigid bodies movement and

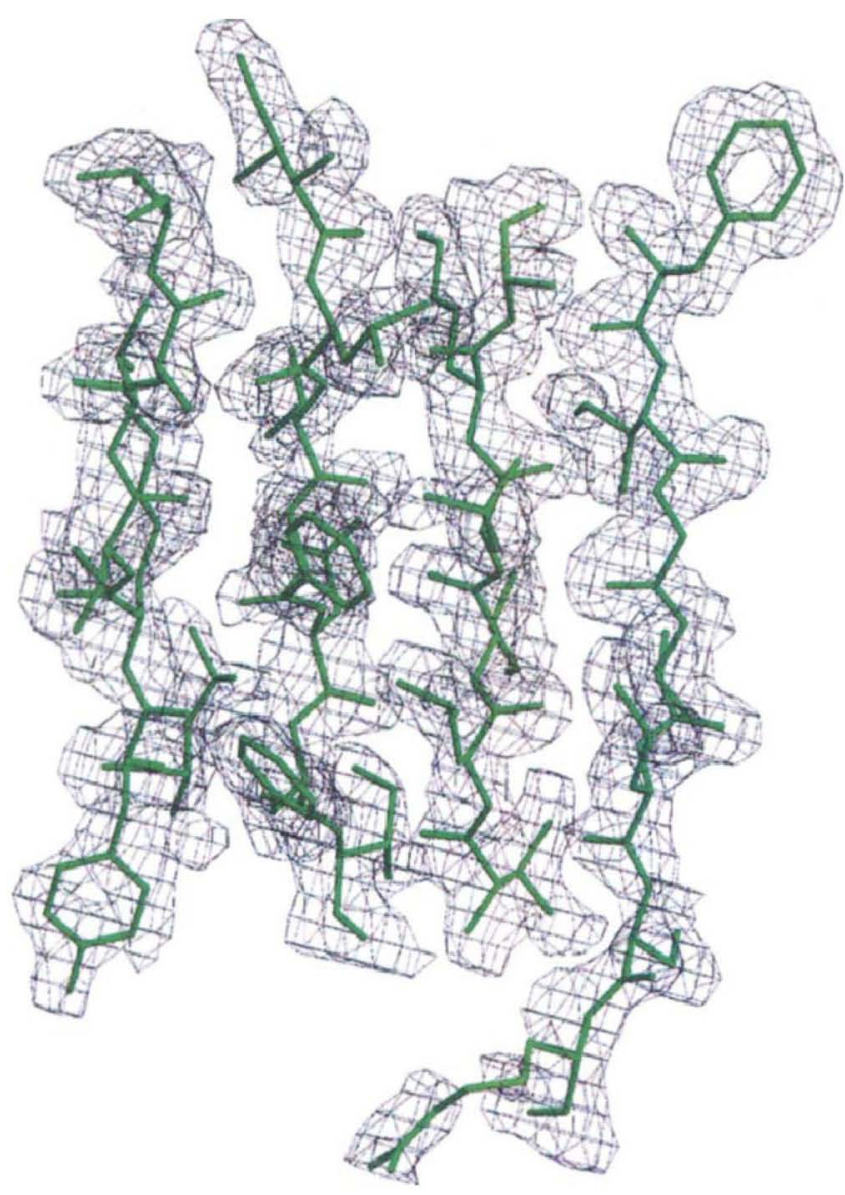

Fig. 2. The initial electron density map, computed between 24.0 and $2.0 \AA$ and contoured at 1.00 , displayed around a portion of the final model of LukFPV.

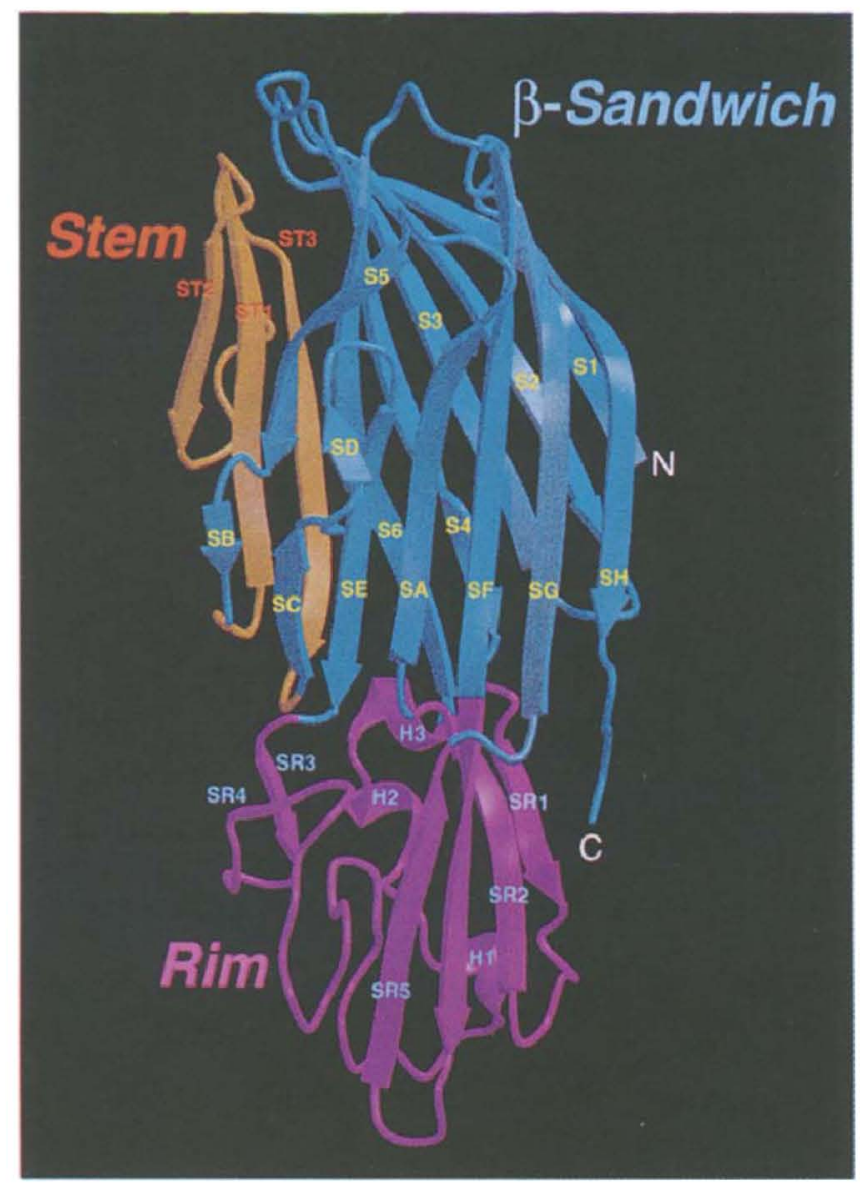

Fig. 3. Ribbon representation of LukF-PV with the $\beta$-sandwich, rim and stem domains colored in cyan, violet and orange, respectively.

adopt different relative orientations in the watersoluble monomeric protein (LukF-PV) and the assembled toxin $(\alpha-H L)$.

Based on this superimposition, a sequence alignment of the two proteins was performed. It was extended to all class $\mathrm{F}(\approx 70 \%$ identity) and class S $(59-75 \%$ identity) proteins. These two protein classes only present $26-30 \%$ identity between each other. The multiple sequence alignment revealed the conservation of several residues that play an important structural role (Table 2). The side-chains of residues from a first group (Ile59, Tyr82, Tyr99, Pro101, Tyr149, Leu153, Trp164, Leu216, Phe221, Pro223, Phe225, and Tyr245) form a continuous hydrophobic patch which involves all the strands in the $\beta$-sandwich domain, except S1, S2, S3, SG and SH. However, the strands S2, $\mathrm{S} 3$, and $\mathrm{S} 4$ are held together by hydrogen bond interactions involving the main chain oxygen atoms of residues 30 and 60, and the invariant Arg247. A second group of residues was identified. The side-chains of Phe76, Trp78, Met192, Phe193, Phe207, Asp250, Tyr252, and Asn265, located at the bottom of the rim domain, provide a number of hydrophobic contacts 
and polar interactions. The conservation of the residues from both groups and of their interactions might be regarded as folding determinants of the $\beta$-sandwich and the rim domains.

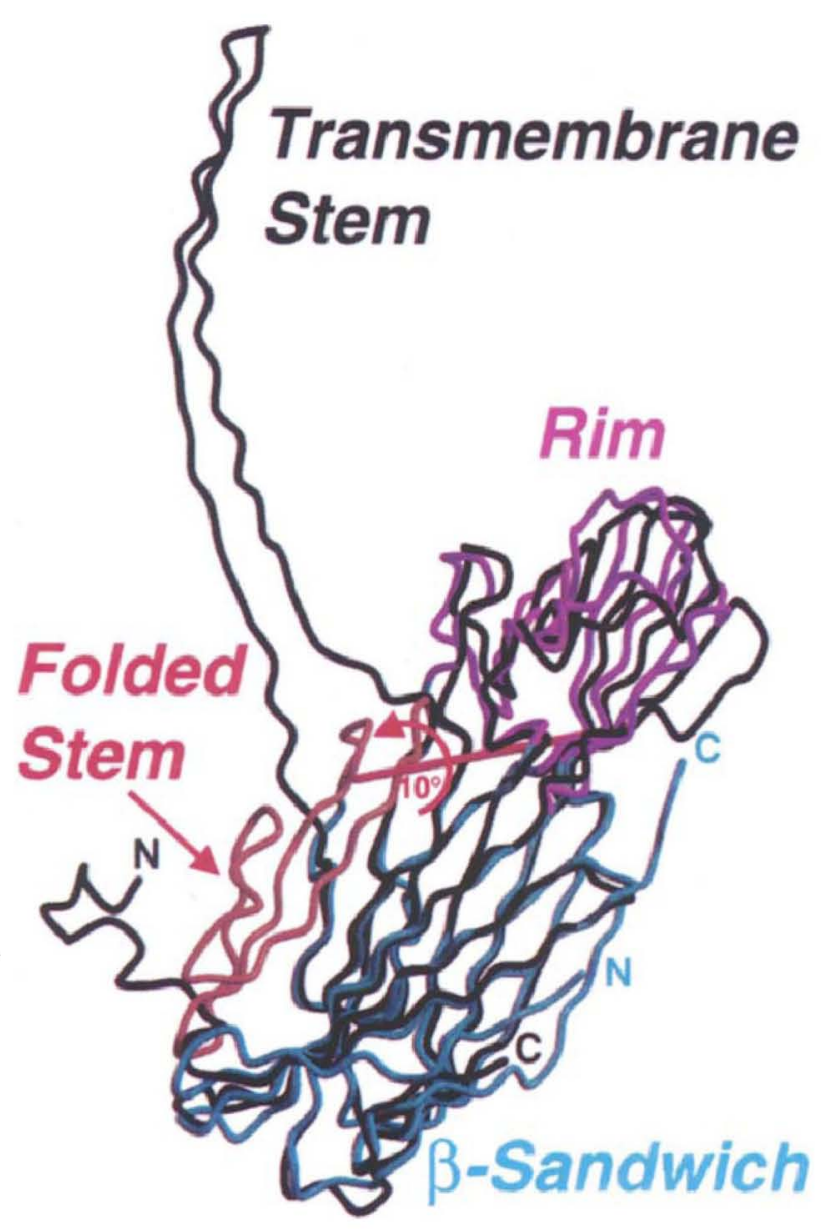

Fig. 4. Superposition ( $\beta$-sandwich domains) of LukF-PV (colored as in Figure 3 ) and one protomer of $\alpha$-hemolysin (black). The rotation axis and the angular range required to fit the rim domains are depicted in red.

\section{Conformational changes in the stem region during assembly}

Pore formation is commonly described as a four-step process involving the water-soluble secreted form, the membrane-bound monomer, an oligomeric pre-pore, and finally, the transmembrane pore (Walker et al., 1992; Valeva et al., 1997). The three-dimensional structures of LukF-PV and of the $\alpha$-HL homoheptamer illustrate the molecular species at the first and at the last step of this process. The stem region, also known as the glycine-rich stem, forms two $55 \AA$ long antiparallel $\beta$-strands in each pore-forming $\alpha$-HL protomer. These strands protrude from the protein core (Figure 4) and constitute one building unit of the membrane-spanning 14-strand $\beta$-barrel (Song et al., 1996). In contrast, the stem region of the water-soluble LukF-PV forms a three-stranded antiparallel $\beta$-sheet and constitutes the third domain of the protein. It is packed onto the convex face of the $\beta$-sandwich domain (Figure 3 ). The resulting stem/ $\beta$-sandwich interface is mainly stabilized through van der Waals interactions between hydrophobic residues. In addition, this interface is tightened at each side by a set of polar interactions. At one edge, the side-chain of Asp43 (strand S3 of the $\beta$-sandwich domain) is at hydrogen bond distance to the main chain oxygen atom of residue 119 and to the phenolic group of Tyr116 (strand ST1 of the stem). At the other edge of the interface, hydrogen bonds are exchanged between the side-chains of Thr151 (strand SC) and Tyr144 and Gln146 (strand ST3 from the folded stem). The invariance of these residues in $\alpha-\mathrm{HL}$ and class $\mathrm{F}$, class $\mathrm{S}$ components, suggests that the fold of the stem domain should be similar in all the secreted monomeric water-soluble proteins.

A search for structural homology in the Protein Data Bank revealed a significant similarity of the stem domain with toxins isolated from snake venom, despite very weak sequence homology. The highest structural similarity was displayed by erabutoxin A (PDB code

Table 2. Residues involved in the conservation of the core domains within the superfamily of staphylococcal pore-forming toxins.

\begin{tabular}{|c|c|c|c|c|c|c|c|c|c|c|c|c|}
\hline \multicolumn{13}{|l|}{$\beta$-sandwich } \\
\hline Residue No & 59 & 82 & 99 & 101 & 149 & 153 & 164 & 216 & 221 & 223 & 225 & 245 \\
\hline Conservation ${ }^{1}$ & 1 & $C$ & $c$ & c & C & $c$ & 1 & 1 & 1 & 1 & 1 & 1 \\
\hline Location & $\$ 4$ & SA & 55 & 55 & SC & SC & SE & $\mathrm{H} 3$ & 56 & S6 & 56 & SF \\
\hline \multicolumn{13}{|l|}{ Rim } \\
\hline Residue No & 76 & 78 & 192 & 193 & 207 & 250 & 252 & 265 & & & & \\
\hline Conservation ${ }^{1}$ & $C$ & 1 & $c$ & 1 & 1 & 1 & $C$ & $c$ & & & & \\
\hline Location & SR2 & SR2 & 2 & 2 & 2 & SF & SF & SR5 & & & & \\
\hline
\end{tabular}

\footnotetext{
1 I, invariant; $C$, conserved.

${ }^{2}$ These residues are located in the polypeptide stretch that caps the open-face sandwich, and at the interface to SR2 and SR5.
} 
5EBX) and toxin $\gamma$ (1TGX), a short $\alpha$-neurotoxin and a cardiotoxin found in the venoms of sea snake Laticauda semifasciata and of the cobra Naja nigricollis, respectively. The molecular architecture of these 60-70 amino-acid proteins is known as the three finger fold (Rees and Bilwes, 1993). The three central $\beta$-strands, and loops II and III of these toxins, whose conformation is constrained by four disulfide bridges, encompass the fold of the stem in LukF-PV (Figure 5). The disulfide bond found between Cys 43 and Cys 54 in erabutoxin A, anchors loop III to the core of the molecule. In LukF-PV, there is no structural constraint that could stabilize the corresponding long solvent-exposed loop of the glycine-rich stem (residues 127-137 between strands ST2 and ST3). The occurrence of five glycines in this peptide stretch (over the eight found between residues 102 and 147) may confer important conformational flexibility. Indeed, Ser129 and the three consecutive glycine residues display the highest temperature factors in the structure and no clear elec-

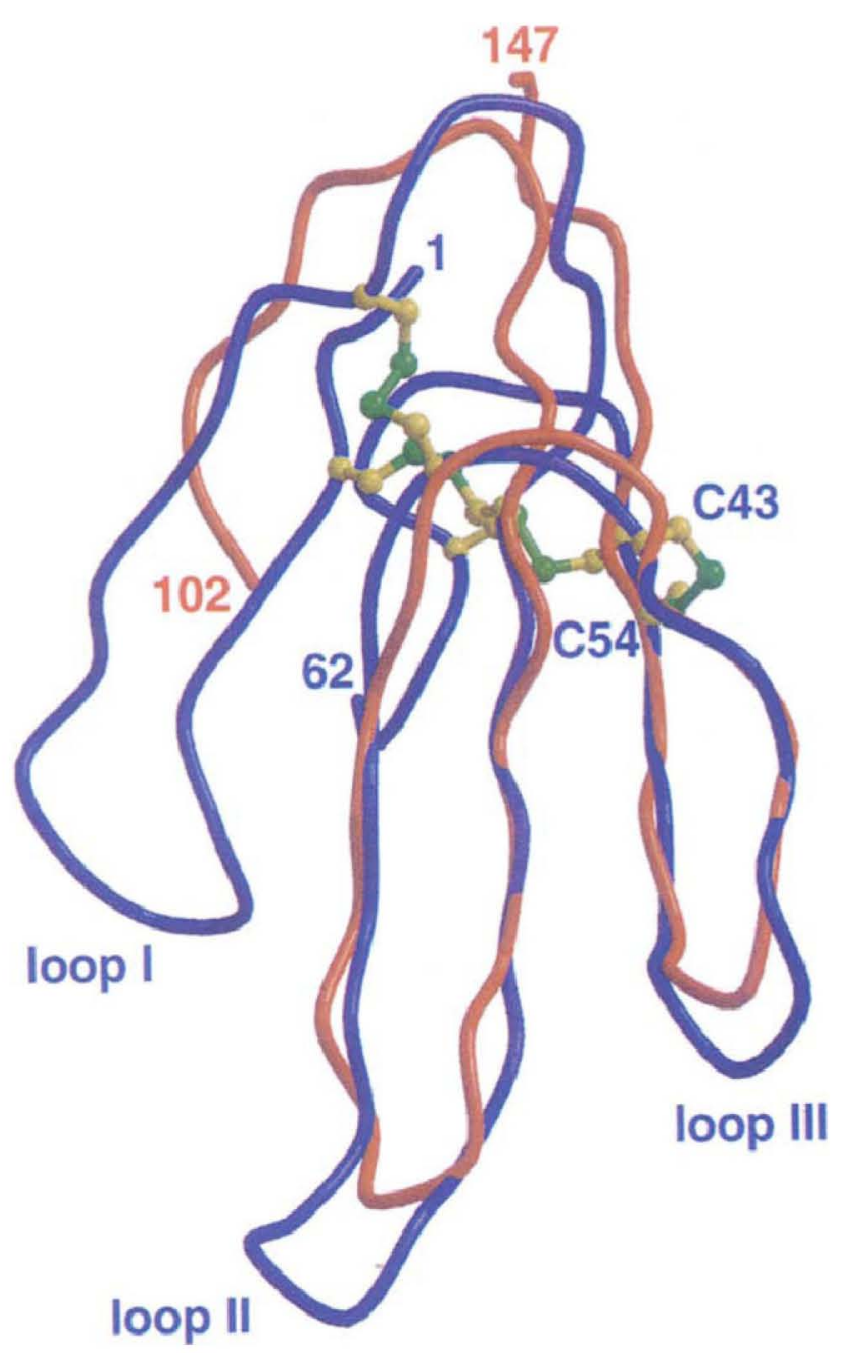

Fig. 5. The stem domain of LukF-PV (orange) superimposed on the threedimensional structure of erabutoxin A (blue). tron density could be assigned to residues 133-135. Flexibility of the polypeptide chain in this region should be invoked since SDS-PAGE electrophoresis of dissolved crystals only revealed a single protein band corresponding to the full-length protein.

Erabutoxin is a postsynaptic curare-mimetic protein which binds specifically to peripheral nicotinic acetylcholine receptors, thus preventing the binding of acetylcholine. Cardiotoxins (Kumar et al., 1997) are also called cytotoxins and cause heart failure. They have numerous pharmacological properties and exhibit a large spectrum of biological activities. Their targets, unlike those of neurotoxins, and mode of interaction with membranes are not well understood. However, it has been established that cardiotoxins elicit biological response from cells by primarily binding to the membrane surface owing to a pattern of hydrophobic and basic residues. The possible functional significance of the fold similarity between these toxins and the stem of LukF-PV, with respect to protein-membrane interactions, remains to be documented.

\section{Functional implications}

Pore formation with staphylococcal toxins requires unfolding of the stem region. The differences in solvent accessibilities of the residues of this domain in its folded and extended conformation, indicate that the side-chains which will be oriented toward the non polar part of the lipid bilayer are, for most of them, involved in the interface between the stem and the $\beta$ sandwich domains. The protein-membrane interactions likely promote the drastic conformational transitions leading to unfolding of the stem domain and to the formation of significant protomer-protomer interfaces in the oligomeric species (Song et al., 1996).

A significant structural difference between LukF-PV and the $\alpha-\mathrm{HL}$ protomer was observed in their $\mathrm{N}$ terminal regions. In monomeric LukF-PV, this region constitutes the outermost external strand (S1) of the $\beta$-sandwich domain. In contrast, the $\mathrm{N}$-terminal latch (residues 1-16) of $\alpha$-HL in the heptameric assembly has no defined secondary structure and forms numerous interactions with adjacent protomers within the lumen of the cap domain (Song et al., 1996). It was suggested that the transition from the soluble monomeric form of $\alpha-H L$ to the pore-forming heptameric structure was related to a conformational change of the $\mathrm{N}$-terminal region (Cheley et al., 1997). Gouaux and coworkers proposed that the stem is still folded in the heptameric pre-pore intermediate, and that its insertion into the membrane may occur with the concomitant rearrangement of the $\mathrm{N}$-terminal region in the cap domain (Olson et al., 1999). According to the structure of LukF-PV, this process would imply that strand S1 
dissociates from its antiparallel strand S2. We have examined the possibility that the $\mathrm{F}$ and $\mathrm{S}$ components may form homo- or heteroheptameric pores similar to that of $\alpha-\mathrm{HL}$. Our modeling approaches revealed that the formation of these heptamers was unlikely (Pédelacq et al., 1999), which would agree with the proposal that the oligomeric bi-component toxins contain equimolar proportions of $\mathrm{F}$ and $\mathrm{S}$ components in hexameric assemblies (Sugawara et al., 1997; Ferreras et al., 1998). Based on a canonical 12-stranded antiparallel $\beta$-barrel (Sansom and Kerr, 1995), a heterohexamer of PVL was modeled without altering the position of strand S1 (Pédelacq et al., 1999). Its topological and geometrical features underlined inter-protomer interactions involving the folded $\mathrm{N}$-terminal strand. The inner diameter of $21 \AA$ is in good agreement with the experimental data on $\gamma$-hemolysin (Sugawara et al., 1997) and PVL (Colin et al., 1997).

\section{References}

Cheley, S., Malghani, M.S., Song, L., Hobaugh, M., Gouaux, J. E., Yang, J., Bayley, H.: Spontaneous oligomerization of a staphylococcal $\alpha$-hemolysin conformationally constrained by removal of residues that form the transmembrane $\beta$-barrel. Protein Eng. 10, 1433-1443 (1997).

Colin, D.A., Mazurier, I., Sire, S., Finck-Barbançon, V.: Interaction of the two components of leukocidin from Staphylococcus aureus with human polymorphonuclear leukocyte membranes: sequential binding and subsequent activation. Infect. Immun. 62, 3184-3188 (1994).

Colin, D. A., Meunier, O., Staali, L., Prévost, G., Monteil, H.: Bi-component leukotoxins from Staphylococcus aureus. In: Cold Spring Harbor Laboratory Symposium on Microbial Pathogenesis and Host Response (Maloy et al., eds.), pp. 150. Cold Spring Harbor Laboratory Press, Cold Spring Harbor, New York 1997.

Cooney, J., Kienle, Z., Foster, T. J., O'Toole, P. W.: The gamma-hemolysin locus of Staphylococcus aureus comprises three linked genes, two of which are identical to the genes for the $\mathrm{F}$ and $\mathrm{S}$ components of leukocidin. Infect. Immun. 61, 768-771 (1993).

Ferreras, M., Höper, F., Serra, M.D., Colin, D. A., Prévost, G., Menestrina, G.: The interaction of Staphylococcus aureus bi-component $\gamma$-hemolysins and leucocidins with cells and lipid membranes. Biochim. Biophys. Acta 1414, 108-126 (1998).

Finck-Barbançon, V., Duportail, G., Meunier, O., Colin, D. A.: Pore formation by a two-component leukocidin from Staphylococcus aureus within the membrane of human polymorphonuclear leukocytes. Biochim. Biophys. Acta 1182, 275-282 (1993).

Finck-Barbançon, V., Prévost, G., Piémont, Y.: Improved purification of leukocidin from Staphylococcus aureus and toxin distribution among hospital strains. Res. Microbiol. $142,75-85$ (1991).
Gouaux, E., Hobaugh, M., Song, L.: $\alpha$-Hemolysin, $\gamma$-hemolysin, and leukocidin from Stapbylococcus aureus: distant in sequence but similar in structure. Protein Sci. 12, 2631- 2635 (1997).

Kaneko, J., Muramoto, K., Kamio, Y.: Gene of LukF-PV-like component of Panton-Valentine leukocidin in Staphylococcus aureus P83 is linked with lukM. Biosci. Biotech. Biochem. 61, 541-544 (1997).

König, B., Prévost, G., Piémont, Y., König, W.: Effects of Staphylococcus aureus leukocidins on inflammatory mediator release from human granulocytes. J. Infect. Dis. 171, 607-613 (1995).

Kumar, T.K. S., Jayaraman, G., Lee, C. S., Arunkumar, A. I., Sivaraman, T., Samuel, D., Yu, C.: Snake venom cardiotoxins-structure, dynamics, function and folding. J. Biomol. Struct. Dyn. 15, 431-463 (1997).

Meunier, O., Falkenrodt, A., Monteil, H., Colin, D. A.: Application of flow cytometry in toxinology: pathophysiology of human polymorphonuclear leukocytes damaged by a pore-forming toxin from Staphylococcus aureus. Cytometry 21, 241-247 (1995).

Noda, M., Kato, I., Matsuda, F., Hirayama, T.: Mode of action of staphylococcal leucocidin: relationship between binding of ${ }^{125}$ I-labeled $\mathrm{S}$ and $\mathrm{F}$ components of leucocidin to rabbit polymorphonuclear leukocytes and leucocidin activity. Infect. Immun. 34, 362-367 (1981).

Olson, R., Nariya, H., Yokota, K., Kamio, Y., Gouaux, E.: Crystal structure of staphylococcal LukF delineates conformational changes accompanying formation of a transmembrane channel. Nature Struct. Biol. 6, 134-140 (1999).

Panton, P. N., Valentine, F. C. O.: Staphylococcal toxin. Lancet 222, 506-508 (1932).

Pédelacq, J. D., Maveyraud, L., Prévost, G., Baba-Moussa, L., González, A., Courcelle, E., Shepard, W., Monteil, H., Samama, J. P., Mourey, L.: The structure of a Staphylococcus aureus leucocidin component (LukF-PV) reveals the fold of the water-soluble species of a family of transmembrane pore-forming toxins. Structure 7, 277-287 (1999).

Prévost, G.: The bi-component staphylococcal leucocidins and $\gamma$-hemolysins. In: The comprehensive sourcebook of bacterial protein toxins (J.E.Alouf, J.H.Freer, eds.), pp. 402-418. Academic Press, London 1999.

Prévost, G., Cribier, B., Couppié, P., Petiau, P., Supersac, G., Finck-Barbançon, V., Monteil, H., Piémont, Y.: PantonValentine leucocidin and gamma-hemolysin from Staphylococcus aureus ATCC 49775 are encoded by distinct genetic loci and have different biological activities. Infect. Immun. 63, 4121-4129 (1995).

Rahman, A., Izaki, K., Kamio, Y.: Gamma-hemolysin genes in the same family with lukF and lukS genes in methicillin resistant Staphylococcus aureus. Biosci. Biotech. Biochem. 57, 1234-1236 (1993).

Rees, B., Bilwes, A.: Three-dimensional structures of neurotoxins and cardiotoxins. Chem. Res. Toxicol. 6, 385-406 (1993).

Sansom, M. S., Kerr, I. D.: Transbilayer pores formed by betabarrels: molecular modeling of pore structures and properties. Biophys. J. 69, 1334-1343 (1995).

Song, L., Hobaugh, M. R., Shustak, C., Cheley, S., Bayley, H., Gouaux, J.E.: Structure of staphylococcal alpha-hemo- 
lysin, a heptameric transmembrane pore. Science 274 , 1859-1866 (1996).

Staali, L., Monteil, H., Colin, D. A.: The staphylococcal pore-forming leukotoxins open $\mathrm{Ca}^{2+}$ channels in the membrane of human polymorphonuclear neutrophils. J. Membr. Biol. 162, 209-216 (1998).

Sugawara, N., Tomita, T., Kamio, Y.: Assembly of Staphylococcus aureus $\gamma$-hemolysin into a pore-forming ringshaped complex on the surface of human erythrocytes. FEBS Lett. 410, 333-337 (1997).

Tomita, T., Kamio, Y.: Molecular biology of the poreforming cytolysins from Staphylococcus aureus, $\alpha$ - and $\gamma-$ hemolysins and leukocidin. Biosci. Biotech. Biochem. 61, 565-572 (1997).
Valeva, A., Palmer, M., Bhakdi, S.: Staphylococcal alphatoxin: formation of the heptameric pore is partially cooperative and proceeds through multiple intermediate stages. Biochemistry 36, 13298-13304 (1997).

Walker, B., Krishnasastry, M., Zorn, L., Bayley, H.: Assembly of the oligomeric membrane pore formed by staphylococcal alpha-hemolysin examined by truncation mutagenesis. J. Biol. Chem. 267, 21782-21786 (1992).

Woodin, A. M.: Purification of the two components of leucocidin from Staphylococcus aureus. Biochem. J.75, 158-165 (1960).

Woodin, A. M., Wieneke, A. A.: The cation-sensitive phosphatases of the leucocyte cell membrane. Biochem. Biophys. Res. Commun. 33, 558-562 (1968). 